\title{
Acute toxicity of manganese and its role in regulating testicular enzyme activity of male rats at different time points
}

\section{Xiaonian Zhu}

Guilin Medical University

\section{Yonghua He}

Guilin Medical University

\section{Wenxiang Shi}

Guilin Medical University

\section{Lin Yang}

Guilin Medical University

Yi Sun

Guilin Medical University

Chaoyan Ou (D oak009@163.com)

Guilin Medical University https://orcid.org/0000-0003-4104-7721

\section{Research article}

Keywords: manganese, time toxicity, acute toxicity, short-term repeated exposure, testicular enzyme

Posted Date: January 29th, 2020

DOI: https://doi.org/10.21203/rs.2.22170/v1

License: (1) This work is licensed under a Creative Commons Attribution 4.0 International License. Read Full License 


\section{Abstract}

Background: In order to provide scientific basis for toxicity evaluation and prevention of manganese, this study aims to investigate acute toxicity and testicular alkaline phosphatase (ALP), acid phosphatase $(A C P)$, lactic dehydrogenase (LDH) in male rats after manganese exposure at different time points.

Methods: Under strict control of light/darkness (12 h:12 h), the experimental animals were injected intraperitoneally with $\mathrm{MnCl} 2 \cdot 4 \mathrm{H} 2 \mathrm{O}$ at different zeitgeber time (ZT) after adaptive feeding for 7 days. The acute toxicity test was performed by Kunming mice treated with manganese once and observed for 14 days. LD50 was calculated by improved Karber method according to the death of animals in each group. Short-term repeated manganese exposure was conducted by continuous $30 \mathrm{mg} / \mathrm{kg}$ manganese exposure once a day for 21 days. And then the adult SD male rats were killed to detect activities of testicular ALP, ACP and LDH by ELISA at different ZT points the second day after exposure.

Results: Acute toxic reactions of mice exposed to manganese were varied at different $Z T$ points. The LD50 at ZT2, ZT8, ZT14 and ZT20 were $472.0 \mathrm{mg} / \mathrm{kg}, 408.2 \mathrm{mg} / \mathrm{kg}, 303.3 \mathrm{mg} / \mathrm{kg}$ and $358.0 \mathrm{mg} / \mathrm{kg}$, respectively. Furthermore, short-term repeated manganese exposure could induce the activity changes of ACP, ALP and LDH in testes at different ZT points. ALP increased at ZT20 while decreased at other time points $(P<0.05)$. ACP only decreased at ZT2 $(P<0.05)$. LDH increased at ZT2 and ZT8 $(P<0.05)$, but decreased at ZT14 and ZT20 $(P<0.05)$. In addition, all the testicular enzymes except ACP had interactions between manganese and exposure time.

Conclusion: The acute toxicity and function injury of male reproductive caused by manganese exposure are varied at different ZT points. The timing of toxic reaction needs to be considered in the toxicity evaluation of manganese.

\section{Background}

As a kind of heavy metal, manganese $(\mathrm{Mn})$ is considered to be one of the necessary trace elements for human body. Manganese is involved in many important biochemical reactions as a component of metabolic enzymes or agonists [1]. In addition, manganese is a cofactor of many enzymes and necessary for reproduction. Previous study found that hormone secretion blocked by deficient manganese can cause hypaphrodisia, sterility, inhibition of reproductive function and obstruction of sperm maturation [2]. Excessive manganese can accumulate in testicle to disrupt male reproductive function and destroy the testicular structure [3]. These studies show that both deficient and excessive manganese can lead to reproductive dysfunction. In modern toxicology, the time study is becoming a new research focus for metal toxicity [4]. However, no time study has addressed the direct connection between manganese exposure and testicular enzyme activity in the context of reproductive disease.

The activities of alkaline phosphatase (ALP), acid phosphatase (ACP) and lactic dehydrogenase (LDH) in testicular tissue can be used as biomarkers for the injury of male reproductive and the change of sperm quality. Semen ALP, ACP and LDH are positively related to sperm motility and quantity, showing a 
testicular origin of these enzymes [4]. Moreover, the levels of these enzymes in semen indicate the function, integrity and damage of spermatozoa, that is why they are recommended as important biomarkers of sperm quality $[5,6]$. Accumulated evidence indicates these enzymes can be regulated by manganese exposure. Eidi $A$ et al. showed that manganese could significantly attenuate the increase of serum ALP to nearly normal levels, exerting a hepatoprotection against $\mathrm{CCl} 4$-induced liver injury in rats [5]. Li P et al. assessed the relationships between multiple metals burden in human seminal plasma and semen quality parameters. They found manganese concentration was significantly higher in human with fertility problems than that in normal human, while the ACP activity was significantly higher in normal human [6]. Manganese treatment was reported to significantly decrease the cell viability of SK-N-MC cell and increase the release of LDH [7].

Circadian rhythm is a common biorhythm for physiological and behavioral activities of almost all organisms. The biological clock genes are also expressed in testicles and spermatozoa, suggesting circadian rhythm plays an important role in the regulation of sperm development and male reproduction $[8,9]$. Because of circadian rhythm, the body has different sensitivities to the same poison at different times of the day and night [10]. As a result, the toxicity of most exogenous chemicals is related to the exposure time. The toxic reaction of animals to the same dose of chemicals sometimes is of different degrees simply because of different exposure time. It may even lead to a phenomenon called all or none, that highly sensitive at one time point while no reaction at another time point. Therefore, the toxicity of chemicals should be analyzed not only from the dose, but also from the time point of view.

In this study, acute toxicity parameters and testicular enzymes were used as indexes to explore the time toxicity of manganese. The timed acute toxicity and male reproduction in experimental animals exposed to manganese will provide relevant basis for toxicity evaluation, prevention and treatment of manganese.

\section{Methods}

\section{Reagents}

$\mathrm{MnCl}_{2} \cdot 4 \mathrm{H}_{2} \mathrm{O}$ purity greater than $99 \%$ was purchased from Sigma (St. Louis, MO, USA). ACP, ALP and LDH kits were purchased from Lingnan Biological Products (Guangxi, China). BCA kit for protein concentration was purchased from Beyotime Biotechnology (Shanghai, China).

\section{Experimental animals and feeding}

The experimental animals used are of SPF grade and provided by the Experimental Animal Center of Guilin Medical University. The conditions of animal feeding room were as follows: light/darkness (12 h:12 h), temperature $(24 \pm 1)^{\circ} \mathrm{C}$, humidity $(55 \pm 10) \%$. The experimental animals were free to drink and eat during the whole experiment period. When the experiments were finished, the animals were anaesthetized by intraperitoneal injection of pentobarbital sodium $(50 \mathrm{mg} / \mathrm{kg})$ using a 1-mL plastic syringe. After the animals were asleep, they were killed by cervical dislocation. The animals were managed in agreement with the criteria defined in the $\mathrm{NIH}$ publication (no. 85-23, revised in 1985), and the experimental protocol 
was approved by the Ethics Committee for Animal Care of Guilin Medical University (no. GLMC201603027).

\section{Definition of zeitgeber time (ZT)}

The starting time of light is defined as ZTO (equivalent to 7: 00 of Beijing time) [11]. The natural time is converted to ZT. The exposure time points ZT2, ZT8, ZT14 and ZT20 are equivalent to 9: 00, 15:00, 21:00 and 3: 00 of Beijing time, respectively.

\section{Acute toxicity test}

One hundred Kunming mice of 18-22 g were randomly divided into 20 groups after 7 days of adaptive feeding. According to the zeitgeber time points and $0.2 \mathrm{~mL} / 10 \mathrm{~g}$ body weight, the mice were injected intraperitoneally with $250.00 \mathrm{mg} / \mathrm{kg}, 329.56 \mathrm{mg} / \mathrm{kg}, 434.45 \mathrm{mg} / \mathrm{kg}, 572.72 \mathrm{mg} / \mathrm{kg}$ and $754.99 \mathrm{mg} / \mathrm{kg}$ of $\mathrm{MnCl}_{2} \cdot 4 \mathrm{H}_{2} \mathrm{O}$. After exposure, the toxicity and the number of dead animals were closely observed and recorded for 14 days. The $\mathrm{LD}_{50}$ and $95 \% \mathrm{Cl}$ were calculated with death number of animals according to the improved Karber method.

\section{Short-term repeated toxicity test}

Ninety-six healthy adult SD male rats with initial body weight of $251.06 \pm 21.52 \mathrm{~g}$ were selected for the test. After adaptive feeding for 1 week, animals were randomly divided into 8 groups (4 control groups and 4 manganese exposure groups) and injected intraperitoneally with distilled water or $30 \mathrm{mg} / \mathrm{kg}$ $\mathrm{MnCl}_{2} \cdot 4 \mathrm{H}_{2} \mathrm{O}$ at the corresponding ZT points for 21 days. The animals were killed for obtaining testes at different $\mathrm{ZT}$ points the second day after exposure. The testes were then stored at $-80^{\circ} \mathrm{C}$ for detecting enzyme activity within 2 weeks.

\section{Detection of ACP, ALP, LDH activity and protein concentration}

Testicular tissue $(0.3 \mathrm{~g})$ on the same side of rats was added with $2.7 \mathrm{~g}$ pre-cooled saline for $10 \%$ tissue homogenate by electric homogenizer at $4^{\circ} \mathrm{C}$. And then the tissue homogenate was centrifugated at 3000 $\mathrm{r} / \mathrm{min}$ for $10 \mathrm{~min}$ and the supernatant was used to determine the activity of ACP, ALP and LDH by ELISA method on 7170A Automatic Biochemical Analyzer (Olympus, Japan). The protein concentration was determined by BCA kit on 721 Spectrophotometer (Olympus, Japan) and used to adjust the activity of above enzymes.

\section{Statistical analysis}

All the data was analyzed by SPSS 16.0 statistical software. Two samples $t$ test and factorial analysis were carried out and $P<0.05$ was considered as statistically significant.

\section{Results}




\section{Toxic reactions of mice in acute toxicity test}

The experimental mice had different degrees of poisoning symptoms after $\mathrm{MnCl}_{2} \cdot 4 \mathrm{H}_{2} \mathrm{O}$ exposure, the mild ones appeared listlessness, emaciation, loss of appetite or abolition, curling up, while standing unstable, hair removal and leg edema in the heavy ones. At later stage of the test, the mice fell on the

ground, curled claws and toes, had leg stiffness and tremor. With dose of $\mathrm{MnCl}_{2} \cdot 4 \mathrm{H}_{2} \mathrm{O}$ increased, all these reactions aggravated aggravation. The earliest symptom appeared at once upon $\mathrm{MnCl}_{2} \cdot 4 \mathrm{H}_{2} \mathrm{O}$ exposure, and death began as early as 20 min and stopped on the 12th day after $\mathrm{MnCl}_{2} \cdot 4 \mathrm{H}_{2} \mathrm{O}$ exposure. We found the dead mice had dark red of blood, light color of muscle, larger and darker of filling gallbladder and punctate bleeding liver or some khaki-yellow liver. There was no obvious pathological change in other organs.

\section{$\mathrm{LD}_{50}$ and $95 \% \mathrm{Cl}$ of mice exposed to manganese}

The death of mice at ZT2, ZT8, ZT14 and ZT20 points was shown in Table 1. As shown in Table 2, the acute toxicity of mice after manganese exposure at ZT14 point was the highest, and the $\mathrm{LD}_{50}(95 \% \mathrm{Cl})$ was $303.30 \mathrm{mg} / \mathrm{kg}(275.30-334.20 \mathrm{mg} / \mathrm{kg})$. The LD $_{50}(95 \% \mathrm{Cl})$ at ZT20 and ZT8 points were 358.01 $\mathrm{mg} / \mathrm{kg}(294.92-434.61 \mathrm{mg} / \mathrm{kg})$ and $399.85 \mathrm{mg} / \mathrm{kg}(315.42-506.89 \mathrm{mg} / \mathrm{kg})$, respectively. The acute toxicity at ZT2 was the least, and the $\mathrm{LD}_{50}(95 \% \mathrm{Cl})$ was $471.95 \mathrm{mg} / \mathrm{kg}(376.14-592.17 \mathrm{mg} / \mathrm{kg})$.

\section{Effects of manganese exposure on testicular ALP, ACP and LDH of SD rats}

As shown in Figure 1, short-term repeated manganese exposure could induce the activity changes of ACP, ALP and LDH in rat testes. However, the changes were varied at different time points. The activity of ALP increased at ZT20 point while decreased at other time points $(P<0.05)$. The activity of ACP was reduced only at ZT2 point $(P<0.05)$, but there was no significant difference in other time points $(P>0.05)$. The activity of LDH increased at ZT2 and ZT8 time points $(P<0.05)$, but decreased at ZT14 and ZT20 time points $(P<0.05)$.

\section{Interactions between testicular enzymes and ZT points after manganese exposure}

Above results show that the activities of testicular ACP, ALP and LDH were varied at different ZT points upon manganese exposure, suggesting there may be some interactions between these testicular enzymes and ZT points. As shown in Table 3 and Figure 2, the changes of ALP and LDH in testicular tissue of rats had interactions between manganese and zeitgeber time points $(P<0.01)$, while the interaction between manganese and ZT points of ACP enzyme was not statistically significant $(P>0.05)$.

\section{Discussion}

The physiological and behavioral activities of organisms are largely affected by circadian rhythm [10], which leads to the toxic reactions of experimental animals are of varied poisoning degrees due to different exposure time to chemicals. Our results show that even if it is only once of manganese 
exposure, the acute toxicities induced by manganese at different ZT points are different. Among them, the acute toxicity at ZT14 is the highest, followed by ZT20 and ZT14, and ZT2 is the least.

Spermatogenesis is a complex process of multitemporal phase, which is closely related to the activity of many enzymes in spermatogenic cells. LDH is the main enzyme that produces energy by glucose metabolism in spermatogenic cells and is one of the enzymes that produce ATP. LDH plays an important role in the metabolic process of sperm survival, movement and fertility, and is a marker predictive of sperm quality $[12,13]$. Another key enzyme ACP is mainly distributed in the supporting cells of spermatogonia. It can be used as an index to measure whether spermatogenesis disorder occurs. In patients with clinical ejaculation disorder, ALP from testes and epididymis can be used as a marker to distinguish oligozoospermia from spermatozoa deficiency [14]. In wild boars, there was a correlation between sperm quality and sperm ALP release under maximum or minimum pressure [15]. Wang Meizhen et al. also reported that the increase of LDH enzyme activity was a crucial indicator of energy metabolism weakening and sperm deformity in spermatogenic cells [16]. The activity decrease of ACP enzyme may be caused by weak activity of sertoli cells, which also results in it as an important marker for the decrease of sperm count. This study indicates that manganese exposure can affect the activities of testicular ACP, ALP and LDH. Our results are consistent with those results of Adedara et al. [17], which shows that excessive manganese exposure could decrease the activities of ALP, ACP and LDH in testes.

Because of biorhythm, circadian rhythm implicates in sperm development and production [18]. We found that the activity changes of ALP, ACP and LDH were varied upon the same dose of manganese exposure at different ZT points. ALP increased at ZT20, but decreased at other time points. ACP only decreased at ZT2, and LDH increased at ZT2 and ZT8 while decreased at ZT14 and ZT20. However, the changes of these enzymes were consistent with the decrease of sperm count and motility [19]. Furthermore, factorial analysis showed that the changes of these enzymes in testicular tissue of rats had interactions between manganese and zeitgeber time points except ACP.

\section{Conclusion}

In summary, there is a difference of acute toxicity exposed to manganese at different zeitgeber time points. Moreover, the injury of male reproductive system caused by manganese is varied at different zeitgeber time points. In future, it is necessary to consider the timeliness of toxic reaction when evaluating the toxicity of manganese.

\section{Abbreviations}

ALP: alkaline phosphatase; ACP: acid phosphatase; LDH: lactic dehydrogenase; ZT: zeitgeber time; Mn: manganese

\section{Declarations}




\section{Ethics approval and consent to participate}

The animals were managed in agreement with the criteria defined in the NIH publication (no. 85-23, revised in 1985), and the experimental protocol was approved by the Ethics Committee for Animal Care of Guilin Medical University (no. GLMC201603027).

\section{Consent for publication}

Not applicable.

\section{Availability of data and materials}

All data generated or analysed during this study are included in this published article.

\section{Competing interests}

The authors declare that they have no competing interests.

\section{Funding}

This work was supported by Natural Science Foundation of Guangxi Province (2018GXNSFAA138075), and Innovation and Entrepreneurship Training Program for College Students in Guangxi Province (201710601106). The funders did not play any role in the design of the study, data collection and interpretation.

\section{Authors' contributions}

$\mathrm{XNZ}$ and CYO made contributions to the conception and design of the study. $\mathrm{LY}$ and $\mathrm{YHH}$ analyzed the data and wrote the first draft of the article. YS and WXS performed the experiments. All the authors read and approved the final manuscript.

\section{Acknowledgements}

Not applicable.

\section{References}

1. Chen P, Chakraborty S, Peres TV, Bowman AB, Aschner M. Manganese-induced Neurotoxicity: From C. elegans to Humans. Toxicol Res. 2015;4(2):191-202.

2. Xie J, Tian C, Zhu Y, Zhang L, Lu L, Luo X. Effects of inorganic and organic manganese supplementation on gonadotropin-releasing hormone-I and follicle-stimulating hormone expression and reproductive performance of broiler breeder hens. Poul Sci. 2014;93(4):959-69.

3. Li Y, Wu J, Zhou W, Gao E. Effects of manganese on routine semen quality parameters: results from a population-based study in China. BMC Public Health. 2012;12:919. 
4. Miura N, Ashimori A, Takeuchi A, Ohtani K, Takada N, Yanagiba Y, et al. Mechanisms of cadmiuminduced chronotoxicity in mice. J Toxicol Sci. 2013;38(6):947-57.

5. Eidi A, Mortazavi P, Behzadi K, Rohani AH, Safi S. Hepatoprotective effect of manganese chloride against CCl4-induced liver injury in rats. Biol Trace Elem Res. 2013;155(2):267-75.

6. Li P, Zhong Y, Jiang X, Wang C, Zuo Z, Sha A. Seminal plasma metals concentration with respect to semen quality. Biol Trace Elem Res. 2012;148(1):1-6.

7. Bahar E, Kim JY, Yoon H. Quercetin Attenuates Manganese-Induced Neuroinflammation by Alleviating Oxidative Stress through Regulation of Apoptosis, iNOS/NF-kappaB and HO-1/Nrf2 Pathways. Int J Mol Sci. 2017;18(9).

8. Baburski AZ, Sokanovic SJ, Andric SA, Kostic TS. Aging has the opposite effect on cAMP and cGMP circadian variations in rat Leydig cells. J Comp Physiol B. 2017;187(4):613-23.

9. Zhang WX, Chen SY, Liu C. Regulation of reproduction by the circadian rhythms. Sheng li xue bao. 2016;68(6):799-808.

10. Dolatshad H, Davis FC, Johnson MH. Circadian clock genes in reproductive tissues and the developing conceptus. Reprod Fertil Dev. 2009;21(1):1-9.

11. Minaya DM, Robertson KL, Rowland NE. Circadian and economic factors affect food acquisition in rats restricted to discrete feeding opportunities. Physiol Behav. 2017;181:10-5.

12. Duan C, Goldberg E. Inhibition of lactate dehydrogenase C4 (LDH-C4) blocks capacitation of mouse sperm in vitro. Cytogenet Genome Res. 2003;103(3-4):352-9.

13. Pesch S, Bergmann M, Bostedt $H$. Determination of some enzymes and macro- and microelements in stallion seminal plasma and their correlations to semen quality. Theriogenology. 2006;66(2):307-13.

14. El-Beshbishy HA, Aly HA, El-Shafey M. Lipoic acid mitigates bisphenol A-induced testicular mitochondrial toxicity in rats. Toxicol Ind Health. 2013;29(10):875-87.

15. Bucci D, Giaretta E, Spinaci M, Rizzato G, Isani G, Mislei B, et al. Characterization of alkaline phosphatase activity in seminal plasma and in fresh and frozen-thawed stallion spermatozoa. Theriogenology. 2016;85(2):288-95 e2.

16. Wang M, Jia X. Effects of low-dose and long-term lead $(\mathrm{Pb})$ exposure on testicular enzymes in male Rana nigromaculata. Acta Scientiae Circumstantiae. 2012;32(3):751-6.

17. Adedara IA, Subair TI, Ego VC, Oyediran O, Farombi EO. Chemoprotective role of quercetin in manganese-induced toxicity along the brain-pituitary-testicular axis in rats. Chem Biol Interact. 2017;263:88-98.

18. Alavi-Shoushtari SM, Rezai SA, Ansari MH, Khaki A. Effects of the seminal plasma zinc content and catalase activity on the semen quality of water buffalo (Bubalus bubalis) bulls. Pak J Biol Sci. 2009;12(2):134-9.

19. Shi W, Ou C, Lu F, Zhou J, Wang J, Wang C, et al. Effects of manganese exposure at different time points on sperm quality and sex hormones in rats. Modern Preventive Medicine. 2018;45(11):203942,46 . 


\section{Tables}

Table 1 Death of mice after intraperitoneal injection of $\mathrm{MnCl}_{2} \bullet 4 \mathrm{H}_{2} \mathrm{O}$ at different time points

\begin{tabular}{|c|c|c|c|c|c|c|c|c|}
\hline \multicolumn{2}{|c|}{ Group } & \multicolumn{2}{|c|}{ Dose } & \multirow[t]{2}{*}{ Number of mice } & \multirow[t]{2}{*}{ Death number } & \multirow[t]{2}{*}{ Death rate $(p)$} & \multirow[t]{2}{*}{ Survival rate $(q)$} & \multirow[t]{2}{*}{$\mathrm{p} \times \mathrm{q}$} \\
\hline & & $\mathrm{mg} / \mathrm{kg}$ & logarithm & & & & & \\
\hline \multirow[t]{5}{*}{$\mathrm{Z} 2$} & 1 & 250.0 & 2.3979 & 5 & 0 & 0 & 1 & 0 \\
\hline & 2 & 329.6 & 2.5179 & 5 & 2 & 0.4 & 0.6 & 0.24 \\
\hline & 3 & 434.5 & 2.6379 & 5 & 2 & 0.4 & 0.6 & 0.24 \\
\hline & 4 & 572.7 & 2.7579 & 5 & 3 & 0.6 & 0.4 & 0.24 \\
\hline & 5 & 755.0 & 2.8779 & 5 & 4 & 0.8 & 0.2 & 0.16 \\
\hline \multirow[t]{5}{*}{$\mathrm{Z} 8$} & 1 & 250.0 & 2.3979 & 5 & 1 & 0.2 & 0.8 & 0.16 \\
\hline & 2 & 329.6 & 2.5179 & 5 & 2 & 0.4 & 0.6 & 0.24 \\
\hline & 3 & 434.5 & 2.6379 & 5 & 3 & 0.6 & 0.4 & 0.24 \\
\hline & 4 & 572.7 & 2.7579 & 5 & 4 & 0.8 & 0.2 & 0.16 \\
\hline & 5 & 755.0 & 2.8779 & 5 & 4 & 0.8 & 0.2 & 0.16 \\
\hline \multirow[t]{5}{*}{ Z14 } & 1 & 250.0 & 2.3979 & 5 & 0 & 0 & 1 & 0 \\
\hline & 2 & 329.6 & 2.5179 & 5 & 4 & 0.8 & 0.2 & 0.16 \\
\hline & 3 & 434.5 & 2.6379 & 5 & 5 & 1 & 0 & 0 \\
\hline & 4 & 572.7 & 2.7579 & 5 & 5 & 1 & 0 & 0 \\
\hline & 5 & 755.0 & 2.8779 & 5 & 5 & 1 & 0 & 0 \\
\hline \multirow[t]{5}{*}{ Z20 } & 1 & 250.0 & 2.3979 & 5 & 1 & 0.2 & 0.8 & 0.16 \\
\hline & 2 & 329.6 & 2.5179 & 5 & 2 & 0.4 & 0.6 & 0.24 \\
\hline & 3 & 434.5 & 2.6379 & 5 & 3 & 0.6 & 0.4 & 0.24 \\
\hline & 4 & 572.7 & 2.7579 & 5 & 5 & 1 & 0 & 0 \\
\hline & 5 & 755.0 & 2.8779 & 5 & 5 & 1 & 0 & 0 \\
\hline
\end{tabular}

Table $2 \mathrm{LD}_{50}$ and $95 \% \mathrm{CI}$ of mice after intraperitoneal injection of $\mathrm{MnCl}_{2} \bullet 4 \mathrm{H}_{2} \mathrm{O}$ at different zeitgeber time 


\begin{tabular}{ccc}
\hline ZT & LD $_{50}(\mathrm{mg} / \mathrm{kg})$ & 95\%CI (mg/kg) \\
\hline ZT2 & 471.95 & $376.14-592.17$ \\
ZT8 & 399.85 & $315.42-506.89$ \\
ZT14 & 303.32 & $275.30-334.20$ \\
ZT20 & 358.01 & $294.92-434.61$ \\
\hline
\end{tabular}

Table 3 Factorial analysis on the effects of manganese and exposed time points on ALP, ACP and LDH in testes of SD rats

\begin{tabular}{ccccccc}
\hline \multirow{2}{*}{ Source } & \multicolumn{2}{c}{ ALP } & \multicolumn{2}{c}{ ACP } & \multicolumn{2}{c}{ LDH } \\
\cline { 2 - 7 } & F & $P$-value & F & $P$-value & F & $P$-value \\
\hline Adjusted model & 60.125 & 0.000 & 6.487 & 0.000 & 82.189 & 0.000 \\
Intercept & $4.098 \mathrm{E} 3$ & 0.000 & $5.339 \mathrm{E} 3$ & 0.000 & $1.622 \mathrm{E} 4$ & 0.000 \\
Mn & 33.438 & 0.000 & 1.163 & 0.293 & 0.555 & 0.464 \\
ZT & 113.767 & 0.000 & 12.363 & 0.000 & 64.333 & 0.000 \\
Mn*ZT & 16.072 & 0.000 & 2.858 & 0.060 & 124.340 & 0.000 \\
\hline
\end{tabular}

Figures 
a

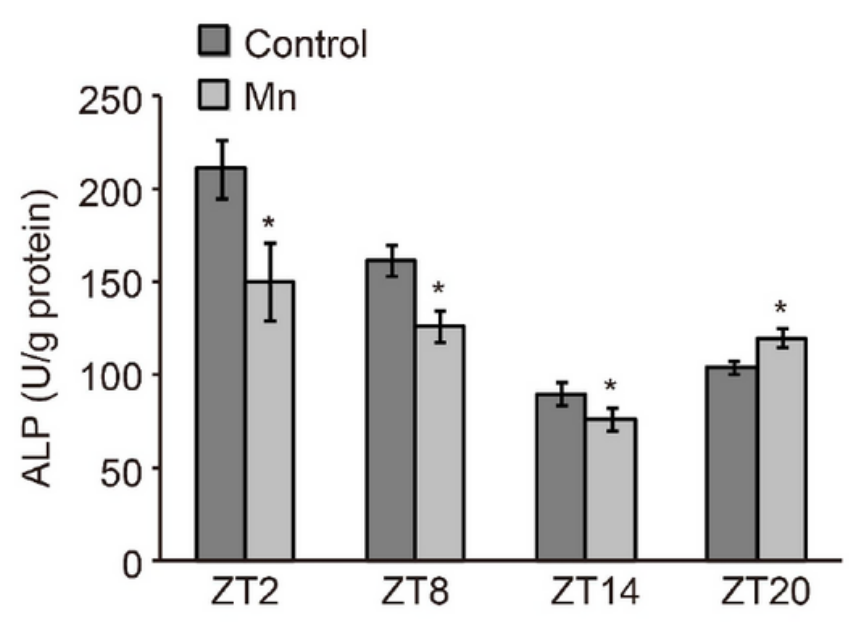

b

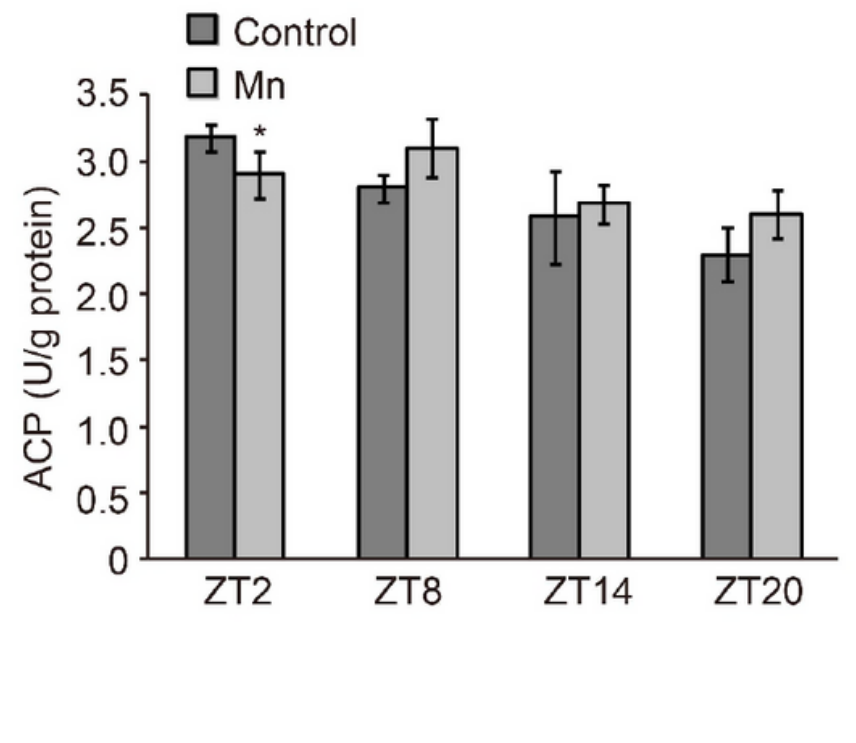

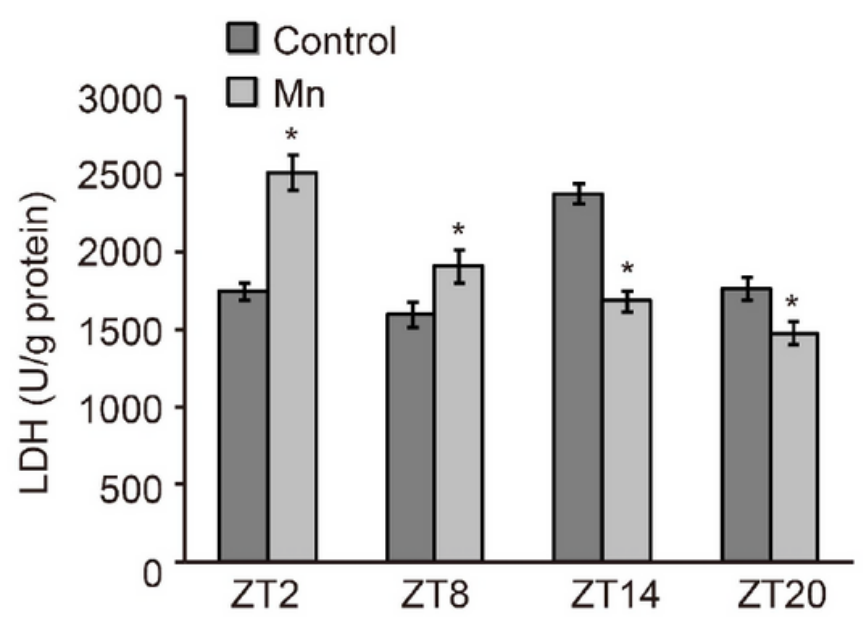

Figure 1

Effects of manganese (Mn) exposure on testicular ALP, ACP and LDH of SD rats at different ZT points.

(a) The activity of testicular ALP upon manganese exposure. (b) The activity of testicular ACP upon manganese exposure. (c) The activity of testicular LDH upon manganese exposure. ${ }^{*}, P<0.05$ is based on the Student $t$ test compared to the control. All results are from three independent experiments. 
a

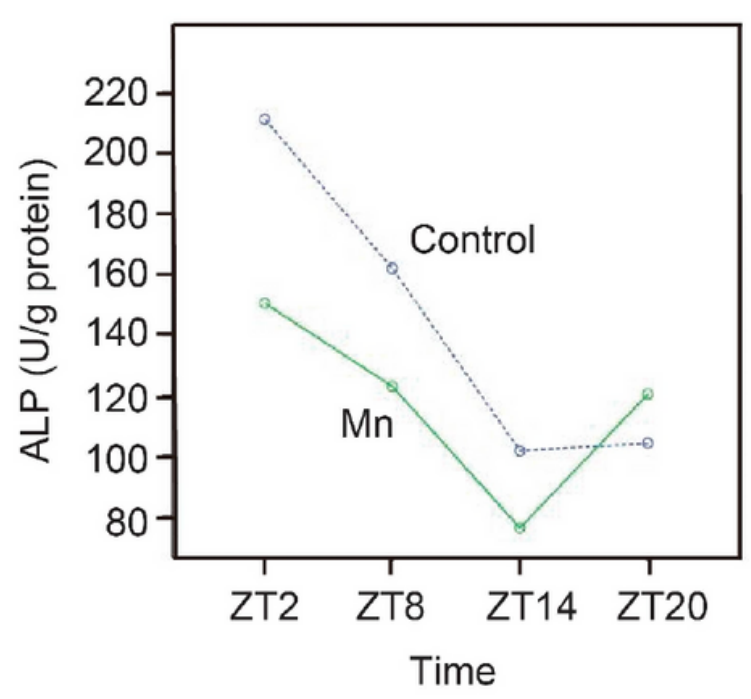

b

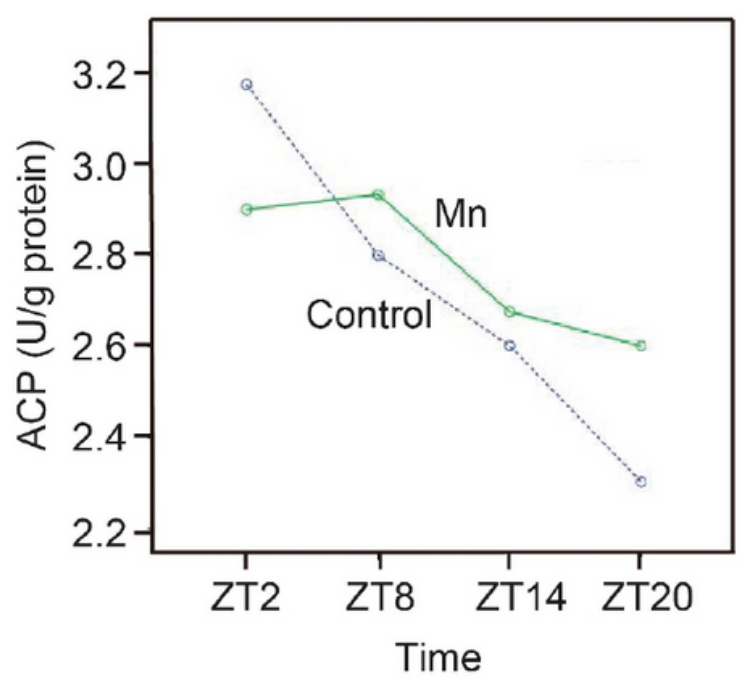

C

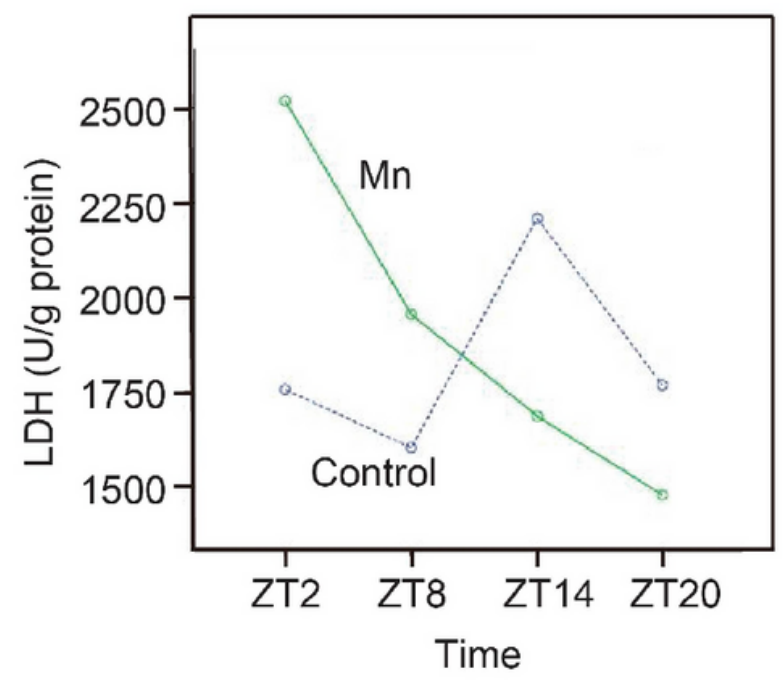

Figure 2

Interactions between testicular enzymes and ZT points after manganese exposure. (a) Interaction between testicular ALP and ZT points upon manganese exposure. (b) Interaction between testicular ACP and ZT points upon manganese exposure. (c) Interaction between testicular LDH and ZT points upon manganese exposure.

\section{Supplementary Files}

This is a list of supplementary files associated with this preprint. Click to download. 
- NC3RsARRIVEGuidelinesChecklistfillable.pdf

Page $13 / 13$ 